\title{
Technological innovation for soil/sediment remediation
}

\author{
Binoy Sarkar ${ }^{1,2} \cdot$ Daniel C. W. Tsang $^{3} \cdot$ Hocheol Song $^{4} \cdot$ Shiming Ding ${ }^{5} \cdot$ Meththika Vithanage $^{6}$
}

Received: 24 October 2019 / Accepted: 24 October 2019/Published online: 12 Novermber 2019

(C) Springer-Verlag GmbH Germany, part of Springer Nature 2019

Soil and sediment pollution, with an ever-increasing number of contaminants, has been a serious issue facing humankind in the current century. Rapid industrialization in all sectors, including agriculture, accompanied by radical acceptance of chemicalbased consumer products by societies over the past centuries has created the mountainous issue of contamination in our air, water, soil, and sediment. The number of contaminated sites has been rising alarmingly in many developed and developing countries impacting billions of lives. Although the awareness about soil/sediment pollution issues and strategies addressing them have evolved encompassing a wide range of guidelines and policies in various countries over the last few decades, the actions taken seem to be inadequate. Most of the currently available soil/sediment remediation technologies are expensive and beyond the economic capacity of private and public stakeholders, and the issue is acute in developing countries of the world. Therefore, innovation in cost-effective technologies for tackling the soil/sediment problem at various real-world contamination scales is an urgent need for the global scientific community.

The present special issue "Technological innovation in soil/sediment pollution" compiles six selected papers covering a breath of topics on novel soil/sediment intervention

Binoy Sarkar

b.sarkar@sheffield.ac.uk

1 Department of Animal and Plant Sciences, The University of Sheffield, Western Bank, Sheffield S10 2TN, UK

2 Present address: Lancaster Environment Centre, Lancaster University, Lancaster LA1 4YQ, UK

3 Department Civil and Environmental Engineering, Hong Kong Polytechnic University, Hung Hom, Kowloon, Hong Kong

4 Sejong University, Seoul, Republic of Korea

5 State Key Laboratory of Lake Sciences, Chinese Academy of Sciences, Nanjing Institute of Geography and Limnology, Nanjing 210008,, People's Republic of China

6 Ecosphere Resilience Research Center, University of Sri Jayewardenepura, Nugegoda 10250,, Sri Lanka strategies in order to remediate both organic and inorganic contaminants. The selected papers were presented at the "CLEAR 2018" (Contaminated Land, Ecological Assessment and Remediation) conference held in Hong Kong during 16-18 August 2018 and underwent the regular peer-review process of the Journal of Soils and Sediments. A brief introduction of the selected papers is given below:

1. Awasthi et al. (2019) assessed the effect of various amendments including composts made of wheat straw biochar on the bioavailability and uptake of $\mathrm{Cd}$ and $\mathrm{Zn}$ by Chinese cabbage grown in smelter-contaminated soils. The authors found that the biochar compost with nitrogen addition was remarkably effective in reducing the bioavailability of $\mathrm{Cd}$ and $\mathrm{Zn}$ in comparison with chemical nitrogenous fertilizer application alone.

2. Through systematic experiments complemented with a modelling approach, Chen et al. (2019) demonstrated the potential of natural zeolites for the stabilization of mixedcontaminants, including hydrophobic organic contaminants (HOCs), in maricultural sediments. The authors used polydimethylsiloxane as a passive sampler for predicting the bioaccumulation of sediment-associated HOCs in Venerupis philippinaram under natural zeolite treatments, asserting that modification of the zeolites could further improve the effectiveness of HOC stabilization.

3. Gunarathne et al. (2019) showed that the treatment of biochar together with municipal solid waste compost effectively immobilized the bioavailable fraction of trace metals in serpentine soils. The germination index of mung bean and tomato seeds was not influenced by the soil water status or by the amendment ratios, but the vigor of mung bean seedlings was controlled by the soil water status under the above amendments.

4. Liu et al. (2019) investigated the immobilization of contaminants in the sediment of the Maozhou River in China seriously polluted with a variety of metals and metalloids. The authors reported that the stabilization effect of various amendments for metals and metalloids was in the order 
$\mathrm{CaCO}_{3}>$ zeolite $>\mathrm{FeCl}_{2}>$ kaolin $>\mathrm{Ca}(\mathrm{OH})_{2}$ where most of these amendments transferred the contaminants into the immobile residual fraction.

5. Luo et al. (2019) studied the cooperative performance of wood vinegar and biochar in affecting plant growth in the agricultural production system. The authors found that the individual application of wood vinegar or biochar stimulated pepper seedling growth, whereas the co-application of wood vinegar and biochar efficiently stimulated the growth of tomato seedling. The authors recommended further investigations to optimize the wood vinegar and biochar co-application strategy because it could potentially enhance the crop growth and thus improve soil health and food security.

6. Ma et al. (2019) investigated the pollution status of polycyclic aromatic hydrocarbons (PAHs) in dumpsite soils in rural areas of China and verified the effectiveness of phytoremediation using plant species such as Sedum alfredii and Medicago sativa under complex pollution conditions. The authors found that both the above plant species absorbed PAHs from the contaminated soil, and PAH concentrations in these two plant species correlated to the growth conditions of the plants.

The papers compiled in this special issue thus covered multiple innovative and emerging approaches for remediating soil and sediment contaminants. The remediation approaches reported by the authors here included soil amendments with natural and synthetic materials, recycled biomasses and waste materials, and phytoremediation with efficient plant species. The above remediation approaches can be considered as less expensive and more environmentally friendly than many conventional dig and dump, and incineration type approaches. A couple of papers also touched upon the necessity of improving the soil health and food security that, along with clean water, are crucial goals set by the
United Nations for achieving a sustainable development of the world in the coming decades.

Acknowledgments As the Guest Editors, we acknowledge all the authors for their valuable contributions in this special issue. We are grateful to Prof. Philip Owens, Prof. Zhihong Xu (the Editors-in-chief) and all the learned reviewers for their respective actions and constructive feedback on the papers in a timely manner. We also acknowledge Ms. Moira Ledger and Mr. Jesson Austria from the Springer team for their outstanding support in managing the manuscripts of this special issue for publication.

\section{References}

Awasthi MK, Wang Q, Chen HY, Liu T, Awasthi SK, Duan YM, Varjani S, Pandey A, Zhang ZQ (2019) Role of compost biochar amendment on the (im)mobilization of cadmium and zinc for Chinese cabbage (Brassica rapa L.) from contaminated soil. J Soils Sediments. https://doi.org/10.1007/s11368-019-02277-8 (this issue)

Chen YQ, Yu WJ, Jin L, Wang Q, Yin J, Lin JW, Li JY (2019) Stabilization of hydrophobic organic contaminants in sediments by natural zeolites: bioavailability-based assessment of efficacy using equilibrium passive sampling. J Soils Sediments. https://doi.org/10. 1007/s11368-019-02381-9 (this issue)

Gunarathne V, Rajakaruna N, Gunarathne U, Biswas JK, Raposo ZA, Vithanage M (2019) Influence of soil water content and soil amendments on trace metal release and seedling growth in serpentine soil. J Soils Sediments. https://doi.org/10.1007/s11368-019-02349-9 (this issue)

Liu YS, Tang YY, Zhong GS, Zeng H (2019) A comparison study on heavy metal/metalloid stabilization in Maozhou River sediment by five types of amendments. J Soils Sediments. https://doi.org/10. 1007/s11368-019-02310-w (this issue)

Ma JW, Gao C, Yan HX, Li YQ, Chen JJ, Zhao Y, Xia XH (2019) Characteristics, sources, and in situ phytoremediation of polycyclic aromatic hydrocarbon in rural dumpsites. J Soils Sediments. https:// doi.org/10.1007/s11368-019-02326-2 (this issue)

Luo XX, Wang ZY, Meki K, Wang X, Liu BJ, Zheng H, You XW, Li FM (2019) Effect of co-application of wood vinegar and biochar on seed germination and seedling growth. J Soils Sediments. https://doi.org/ 10.1007/s11368-019-02365-9 (this issue)

Publisher's note Springer Nature remains neutral with regard to jurisdictional claims in published maps and institutional affiliations. 